\title{
AVALIAÇÃO DA TENDÊNCIA ESPAÇO-TEMPORAL DA PRECIPITAÇÃO PLUVIOMÉTRICA EM UMA REGIÃO SEMIÁRIDA DO ESTADO DE PERNAMBUCO
}

FERREIRA, Pedro dos Santos - pedro_spe@hotmail.com Universidade Federal do Pernambuco/ UFPE

GOMES, Viviane Pedroso - vivianegomesgeo@gmail.com Universidade Federal do Pernambuco/ UFPE

\author{
GALVÍNCIO, Josiclêda Domiciano - josicleda@hotmail.com
} Universidade Federal do Pernambuco/ UFPE
SANTOS, Antonio Marcos dos - geo_fisica@yahoo.com.br Universidade Federal do Pernambuco/ UFPE
SOUZA, Weronica Meira de - weronicameira@gmail.com Universidade Federal Rural do Pernambuco/ UFRPE

\begin{abstract}
RESUMO: Os eventos extremos de precipitação pluviométrica são frequentemente investigados por parte da comunidade científica devido aos prejuízos socioeconômicos causados pelo excesso ou escassez de chuvas em determinadas regiões do mundo. No Nordeste brasileiro, diversos problemas como migrações, fome e mortes têm relação com as recorrentes secas que, historicamente, assolam a região. Ainda assim, estudos sobre as variabilidades climáticas no Semiárido são escassos e generalistas, sobretudo aqueles onde se busca investigar possíveis relações com as mudanças climáticas globais, uma das maiores ameaças do presente século. Deste modo, a presente pesquisa objetiva analisar a tendência espaço-temporal de diferentes índices de precipitação pluviométrica na em uma região semiárida do estado de Pernambuco e a influência da Temperatura de Superfície do Mar (TSM) dos Oceanos Pacífico e Atlântico na variabilidade pluviométrica da região. Foram calculados nove índices climáticos de precipitação relativos à intensidade diária, DCS, DCC e PRCPTOT com a utilização dos softwares Rclimdex e Climap. O teste Mann-Kendall (MK) foi aplicado neste estudo para detectar possíveis alterações de ordem climática das séries temporais de precipitação. Os índices climáticos foram correlacionados com dados da Temperatura da Superfície do Mar (TSM) dos oceanos Pacífico e Atlântico. Verificou-se significativa variação espacial dos sinais de tendência e nível de significância estatística, indicando diminuição das chuvas na região estudada. Constatou-se que as precipitações com tendências negativas são influenciadas pelas variações da TSM nos oceanos Pacífico e Atlântico, evidenciando que o fenômeno El Niño influencia na redução das chuvas na região, assim como o Dipolo do Atlântico.
\end{abstract}

Palavras- chaves: Teste de Mann-Kendall, Índices pluviais, Temperatura da superfície do mar.

EVALUATION OF THE SPACE-TEMPORAL TENDENCY OF PRECIPITATION IN A SEMI-ARID REGION OF THE STATE OF PERNAMBUCO

ABSTRACT: Extreme rainfall events are often investigated by the scientific community due to the socioeconomic losses caused by the excess or scarcity of rainfall in certain regions of the world. In Brazil's Northeast region, several problems such as migrations, famine and death are related to the recurrent droughts that, historically, devastate the region. Nevertheless, studies on climatic variability in the aforementioned region are scarce and generalist, especially those investigating possible relationships with global climate change, one of the greatest threats of the present century. Thus, the present study aims to analyze the spatial-temporal tendency of different rainfall indices in a semiarid region of the state of Pernambuco (Brazilian Northeast), and the influence of the Pacific and Atlantic Oceans' Sea Surface Temperature (SST) on the region's pluviometric 
variability. Nine climatic precipitation indices were calculated for the daily intensity, DCS, DCC, and PRCPTOT, using software Rclimdex and Climap. The Mann-Kendall (MK) test was applied in this study to detect possible changes in the climatic order of the rainfall time series. The climatic indices were correlated with SST data of the Pacific and Atlantic oceans, and a remarkable variation of trend signals and statistical significance levels throughout the study region was observed, indicating a decrease in rainfall. It was found that rainfall with negative tendencies are shaped by SST variations in the Pacific and Atlantic Oceans, evidencing that the El Niño phenomenon influences rainfall reduction in the region, as well as the Atlantic Dipole.

Keywords: Mann-Kendall test, Index of rainfall, Intertropical Convergence Zone

\section{INTRODUÇÃO}

Os eventos extremos de precipitação pluviométrica são frequentemente investigados por parte da comunidade científica internacional devido aos prejuízos socioeconômicos causados pelo excesso ou escassez de chuvas em diversas regiões do mundo. Um dos grandes desafios corresponde compreender os fenômenos atmosféricos associados as variabilidades climáticas e prevê-los no intuito de minimizar seus efeitos negativos sobre o modo de vida humano (FLATO; MUTTARAK; PELSER, 2017; XAVIER; BARCELLOS; FREITAS, 2014).

A preocupação com a questão tem se intensificado em função das mudanças climáticas. Segundo relatórios publicados pelo Painel Intergovernamental de Mudanças Climáticas (IPCC, 2013), espera-se que o aquecimento global venha a modificar os padrões pluviométricos em diversas regiões do mundo, aumentando a quantidade e intensidade dos eventos extremos climáticos relacionados aos fenômenos de seca ou excesso de chuvas. Por outro lado, a natureza dos efeitos e a capacidade de resposta a eles ainda é incerta, sobretudo quando se leva em consideração a escala regional.

No Brasil, várias cidades e regiões apresentaram registros de eventos extremos relacionados a precipitação pluviométrica, com históricos de mortes e prejuízos socioeconômicos. No município de Duque de Caxias, no Rio de Janeiro, por exemplo, Barcellos et al. (2016) realizaram um diagnóstico temporal dos desastres naturais ocorridos nos últimos 20 anos. Os autores destacaram que o excesso de chuvas para determinados períodos causaram graves prejuízos à população. Quanto a natureza dos fenômenos, verificou-se que 74\% desses eventos ocorreram entre os meses de novembro e fevereiro, com maior frequência em 2009 (20\%). Sobre a origem, 57\% dos desastres foram associados à Zona de Convergência do Atlântico Sul (ZCAS), 29\% a atuação de frentes frias e $14 \%$ a áreas de instabilidade na escala local.

Um outro estudo de relevância foi desenvolvido por Loureiro et al. (2014) para o estado do Pará. Os resultados obtidos pelos autores demonstraram que $66 \%$ dos eventos extremos climáticos ocorreram dentro do período classificado como chuvoso, onde verificou-se a atuação persistente de sistemas atmosféricos como a Zona de Convergência Intertropical (ZCIT), ZCAS e Linhas de Instabilidade (LI). Sobre a LI, os autores destacam ainda que este sistema produziu maiores prejuízos devido as altas taxas de precipitação pluviometria horária.

Recentemente, uma grande seca assolou a região sudeste do país, com destaque para o estado de São Paulo, entre 2013 e 2015, onde este tipo de 
fenômeno não é tão comum. Segundo Marengo et al. (2015), as reduções do volume das chuvas afetaram as vazões de várias bacias hidrográficas, para as quais verificou-se volumes bem inferiores à média histórica. No campo econômico, as estimativas iniciais apontam que 60 mil estabelecimentos industriais, que representam $60 \%$ da composição do Produto Interno Bruto (PIB) paulista, foram afetados pela falta de água. Quanto ao setor de alimentos, produtos como o tomate e alface, apresentaram alta de $30 \%$ nos valores, impulsionados também pela elevação dos custos com a produção de energia elétrica.

Quanto ao Nordeste, esta é uma região que enfrenta graves problemas relacionados a irregularidade das chuvas, que causam secas severas e prolongadas, assim como chuvas excessivas. Os eventos mencionados têm sido associados às anomalias de Temperatura de Superfície do Mar (TSM) do Pacífico equatorial que, na fase positiva (El Niño), favorece a redução da precipitação pluviométrica sobre a região Nordeste, enquanto na fase negativa (La Niña) contribui para a ocorrência de chuvas, algumas vezes acima da média histórica (ANDREOLI; KAYANO, 2007).

Sobre os fenômenos de seca no Nordeste, estes eventos vêm sendo atribuídos principalmente ocorrência de El Niños. Embora a relação entre as fases positivas do Pacífico e a ocorrência de secas no Nordeste tenha sido identificada, Andreoli et al. (2004) destaca que os eventos de El Niño não são capazes, sozinhos, de explicar os extremos negativos de precipitação na região. A hipótese é reforçada a partir da contabilização realizada por Kane (1997) no passado. O autor mostrou que entre 1849 a 1992 ocorreram 46 eventos de El Niños classificados como moderados e fortes. Destes, apenas $45 \%$ realmente coincidiram com períodos em que a cidade Fortaleza, por exemplo, foi assolada por secas de intensidade variada.

A explicação para isso pode ser encontrada em estudos pioneiros como os desenvolvidos por Hastenrath e Heller (1977), Moura e Shukla (1981) Servain (1991) e Nobre, Shukla e 1996), que identificaram relação entre os padrões anômalos de TSM sobre a região tropical do Atlântico e a precipitação no Nordeste. O dinamismo detectado pelos autores corresponde ao que convencionou-se chamar Dipolo do Atlântico, fenômeno em que a convergência de ventos úmidos é influenciada pelas temperaturas do Atlântico Sul e Norte, denominado ZCIT. Um estudo mais recente, desenvolvido por Polzin e Hastenrath (2014), também constatou a influência das anomalias de TSM do Atlântico sobre o nordeste do Brasil.

Segundo dados de Instituto Nacional de Pesquisa Espacial (INPE, 2017), entre os anos de 2002 a 2007 e 2009 a 2010 foram registrados eventos de El Niños que não chegaram a causar secas sobre o Nordeste, isto porque além da intensidade dos fenômenos, as anomalias de TSM do Atlântico aturam favoravelmente para a ocorrência de chuvas na região. Neste caso, ficou claro que dependo da intensidade dos El Niños, o posicionamento da ZCIT pode agravar, minimizar ou até mesmo fazer com que seus efeitos não sejam sentidos no que se refere as taxas de precipitação pluviométrica.

Vale ressaltar que vários pesquisadores têm investigado também os fenômenos atmosféricos no Nordeste sob a perspectiva das mudanças climáticas, onde lançaram mão de métodos estatísticos para análises de tendências e possíveis mudanças no padrão. Nesse sentido, destaca-se o estudo 
desenvolvido por Silva et al. (2016) que investigaram evidências de mudanças climáticas no estado do Maranhão por meio da análise de tendência aplicando teste estatístico de Mann-Kendall. Os resultados demonstraram que em algumas localidades houve redução da precipitação pluviométrica, enquanto para outras verificou-se incremento.

Em Pernambuco, Nóbrega, Farias e Santos (2015) realizaram um estudo voltado para avaliação do clima, onde buscou-se detectar possíveis alterações climáticas a partir da análise de séries pluviométricas. Por meio da aplicação de índices que contabilizaram o número de dias consecutivos secos e chuvosos, assim como a precipitação total anual, os autores observaram que houve significativa variação espacial para os sinais de tendência, que a depender da região do estado, evidenciaram aumento ou diminuição das chuvas.

É importante ressaltar que trabalhos sobre avaliação do padrão climático por meio de métodos estatísticos ainda são limitados no Nordeste, sobretudo para a região semiárida, onde a falta de água é uma realidade marcante e agravada devido a sua estrutura socioeconômica. Também se faz necessário o desenvolvimento de estudos capazes de abarcar os efeitos sazonais dos sistemas atmosféricos que atuam na região, favorecendo ou inibindo as precipitações. Deste modo, a presente pesquisa objetiva analisar a tendência espaço-temporal de diferentes índices de precipitação pluviométrica na em uma região semiárida do estado de Pernambuco e a influência da Temperatura de Superfície do Mar (TSM) dos Oceanos Pacífico e Atlântico na variabilidade pluviométrica da região.

\section{MATERIAL E MÉTODOS}

\subsection{A AREA EM ESTUDO}

A área estudada está localizada no oeste do estado de Pernambuco, com um perímetro de $351.579,5 \mathrm{~km} 2$ e população de aproximadamente 956.220 habitantes (IBGE, 2010). A região é formada por três microrregiões, sendo elas Araripina, Petrolina e Salgueiro (Figura 1). O clima é o tropical semiárido, de baixas latitudes e altitudes (BSh), conforme classificação Köppen (ALVARES et al., 2013). 


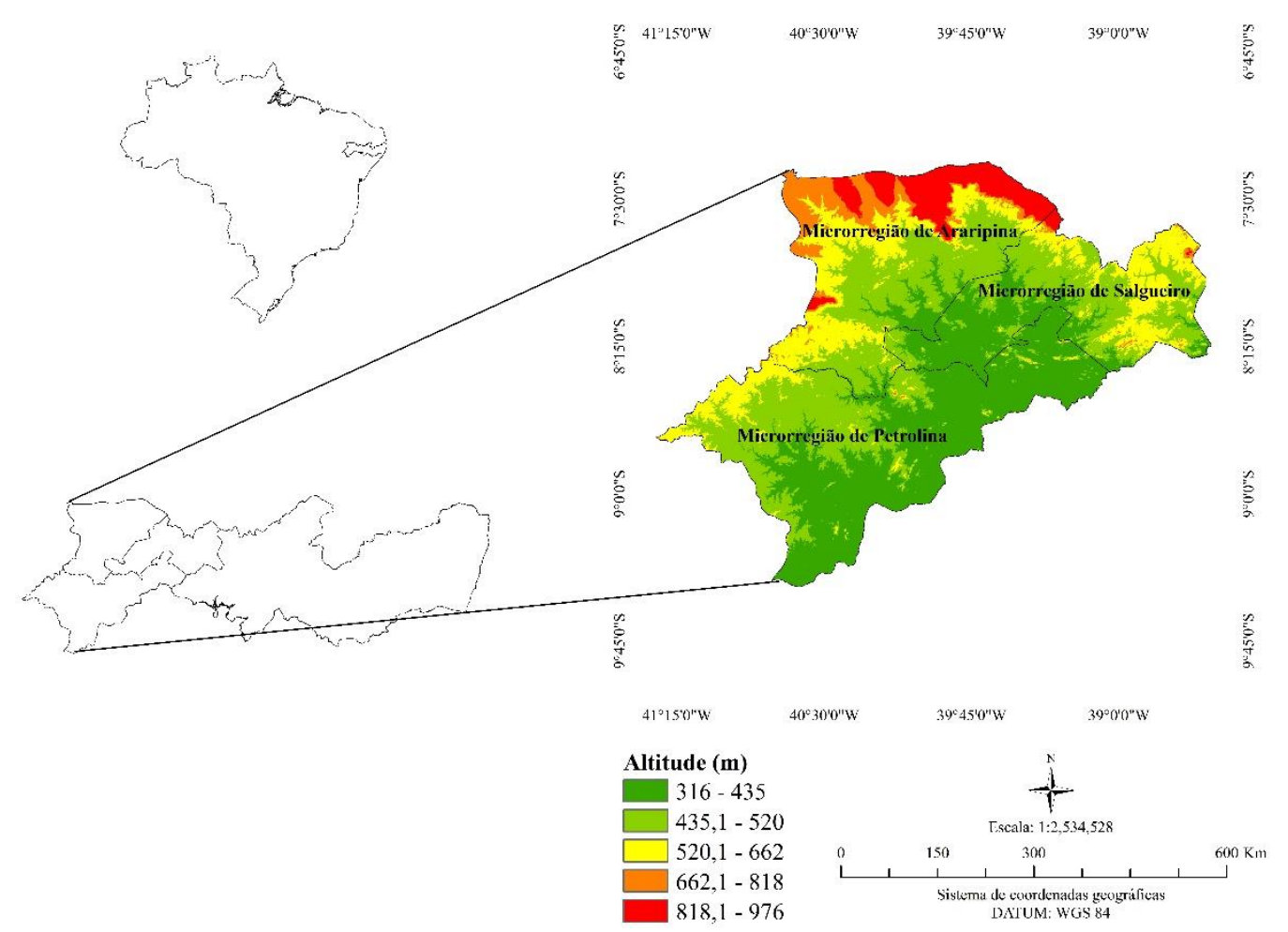

Figura 1 - Localização geográfica das microrregiões de Araripina, Petrolina e Salgueiro, inseridas no estado de Pernambuco.

\subsection{DADOS UTILIZADOS}

Os dados de precipitação pluviométrica utilizados foram obtidos junto à Agência Pernambucana de Águas e Clima (APAC) e Agência Nacional de Água (ANA) e correspondem a dados diários para o período de 1963 - 2014, onde a única exceção é posto de Araripina, cujo a série se estende de 1970 a 2012 (Tabela 1). Para seleção dos postos, adotou-se o critério de percentual de falhas, até $8 \%$, para garantia da confiabilidade dos resultados. Outro critério refere-se a extensão da série histórica, período mínimo de 30 anos, como recomendado pela Organização Meteorológica Mundial (OMM) para estudos sobre o clima.

Tabela 1 - Estações pluviométricas inseridas nas microrregiões de Araripina, Petrolina e Salgueiro com as coordenadas geográficas, $X$ e $Y$ e o percentual de falhas diárias.

\begin{tabular}{ccccc}
\hline Estações & Período & Latitude & Longitude & Falhas (dia) \\
\hline Araripina & $1970-2012$ & -7.46 & -40.42 & $1 \%$ \\
Fazenda São Bento & $1963-2014$ & -8.6161 & -39.9994 & $4,1 \%$ \\
Moreilândia & $1964-2014$ & -7.6075 & -39.55 & $3,3 \%$ \\
Santa Cruz & $1965-2014$ & -8.2406 & -40.3369 & $5,9 \%$ \\
Serrita (1) & $1966-2014$ & -7.9447 & -39.2931 & $2,2 \%$ \\
Serrita (2) & $1967-2014$ & -7.8197 & -39.1486 & $4,1 \%$ \\
\hline
\end{tabular}

Fonte: APAC e ANA. 
$\mathrm{Na}$ análise dos dados, os valores discrepantes, provavelmente relacionados a erros na obtenção da pluviometria ou na transmissão dos mesmos, foram descartados. Para este estudo, optou-se por não realizar o preenchimento das falhas observadas nas séries temporais, visto que estão dentro de um intervalo que não compromete a confiabilidade dos resultados. Outro ponto refere-se a irregularidade espacial e temporal no Semiárido (SILVA; PEREIRA; ALMEIDA, 2012), o que vem a dificultar o preenchimento correto das falhas, sobretudo para o período chuvoso.

\section{3 ÍNDICES DEPENDENTES DA PRECIPITAÇÃO PLUVIAL}

Os índices de precipitação empregados neste estudo são recomendados pela Expert Team on Climate Change Detection Monitoring and Índices (ETCCDMI), e são voltados para estudos sobre mudanças climáticas. A referida entidade sugere 27 índices climáticos, sendo 16 deles relacionados à temperatura e 11 à precipitação. Na presente pesquisa, optou-se por analisar 9 índices de precipitação, conforme a tabela 2 ..

Tabela 2 - Definições e unidades dos índices relativos à precipitação pluviométrica.

\begin{tabular}{cll}
\hline ÍNDICE & \multicolumn{1}{c}{ DESCRIÇÃO } & UNIDADE \\
\hline Pr1 & Número de dias por ano com chuvas $\geq 1$ & $\mathrm{~mm} / \mathrm{dia}$ \\
$\operatorname{Pr} 10$ & Número de dias por ano com chuvas $\geq 10$ & $\mathrm{~mm} / \mathrm{dia}$ \\
$\operatorname{Pr} 20$ & Número de dias por ano com chuvas $\geq 20$ & $\mathrm{~mm} / \mathrm{dia}$ \\
$\operatorname{Pr} 60$ & Número de dias por ano com chuvas $\geq 60$ & $\mathrm{~mm} / \mathrm{dia}$ \\
$\operatorname{Pr80}$ & Número de dias por ano com chuvas $\geq 80$ & $\mathrm{~mm} / \mathrm{dia}$ \\
$\operatorname{Pr} 100$ & Número de dias por ano com chuvas $\geq 100$ & $\mathrm{~mm} / \mathrm{dia}$ \\
DCS & Dias consecutivos secos & dias/ano \\
DCC & Dias consecutivos úmidos & dias/ano \\
PRCPTOT & Precipitação total anual & $\mathrm{mm} /$ ano \\
\hline
\end{tabular}

Fonte: elaborado pelos autores com base no proposto por Zhang e Yang (2004).

O cálculo dos índices referentes à intensidade das chuvas diárias ( $\operatorname{Pr} 1$, Pr20, Pr60, Pr80 e Pr100), assim como a tendência dos mesmos, foi realizado por meio do software Climap. O programa foi desenvolvido por Salvador (2014) como parte de sua tese de doutorado intitulada "Análise da Variabilidade Climática na Nova Fronteira Agrícola do Brasil: Região do Matopiba". De acordo com seu desenvolvedor, o Climap apresenta interface gráfica simples e é elaborado em Python, que é uma linguagem de programação utilizada em softwares de processamento de dados e comunicação.

Os índices DCS, DCC e PRCPTOT foram calculados a partir do software Rclimdex versão 3.2.1, desenvolvido por Byron Gleason do National Climate Data Centre (NCDC) e tem sido utilizado para diversas aplicações, como recursos hídricos e agricultura (SOUZA; AZEVEDO, 2012). A saída do $R$ fornece um conjunto de dados estatísticos referentes à tendência linear calculada pelo método de mínimos quadrados, coeficiente de determinação (R2), erro padrão de estimativa e tendência linear, assim como o nível de significância estatística dos índices climáticos mencionados. Ressalta-se que para a classificação de um 
dia úmido ou seco, o limiar padrão determinado pelo Rclindex é de $1 \mathrm{~mm}$. Ou seja, dias com chuvas < $1 \mathrm{~mm}$ são classificados como secos, enquanto dias de precipitação $\geq 1 \mathrm{~mm}$ são classificados como úmidos.

\subsection{TESTE DE MANN-KENDALL E REPRESENTAÇÃO ESPACIAL E TEMPORAL}

O teste Mann-Kendall (MK) foi utilizado neste estudo para detectar possíveis alterações de ordem climática das séries temporais de precipitação. Para isso, o MK foi aplicado para a precipitação pluviométrica anual e para os meses de dezembro a abril, que concentram maior parte das chuvas no ano, sendo este período classificado como chuvoso (ASSIS; SOUZA; SOBRAL, 2015). A partir da utilização do método estatístico de $M K$, foi possível testar as hipóteses ( $\mathrm{HO}$ e $\mathrm{H} 1$ ) para tendência de longo prazo das séries temporais. Para esta análise, a hipótese é nula ( $\mathrm{HO})$ quando não se observa tendência na amostra de um conjunto de dados $(X 1, X 2, \ldots, X n)$. Já a hipótese $H 1$ refere-se à detecção de alguma tendência monotônica observada no tempo, sendo assim, há rejeição da hipótese $\mathrm{HO}$.

De acordo com Ferrari, Vecchia e Colabone (2012) o MK é o método estatístico mais recomendo para detectar possíveis alterações decorrentes das mudanças climáticas. Uma das principais vantagens do teste de MK corresponde a possibilidade de identificar o ponto exato da mudança.

Dada uma determinada série temporal, xi de $N$ termos ( $1 \leq \mathrm{i} \geq n$ ), o $M K$ é determinado por meio da soma tn de um conjunto de termos $\mathrm{mi}$, relativo ao valor $x i$, pelo qual os termos anteriores $(j<i)$ são inferiores ao mesmo, conforme descrito na Equação (1) seguir:

$$
t n=\sum_{i=1}^{n-1} \sum_{j-i+1}^{n} \operatorname{sign}(x j-x i)
$$

Em séries temporais com grande número de termos $(N)$, sob a hipótese nula HO de ausência de tendência, tn apresenta uma distribuição normal com média $E(t n)=0$ e variância:

$$
\operatorname{VAR}_{\mathrm{tn}}=\sqrt{(\mathrm{n} / 18)(\mathrm{n}-1)(2 \mathrm{n}-5)}
$$

Para rejeição da hipótese nula, é aplicado o teste de significância estatística de tn por meio de um teste bilateral para grandes valores $U(t n)$, por meio de:

$$
U(t n)=(t n-E(t n)) /(\operatorname{var}(t n)) 1 / 2
$$

Na versão sequencial, duas curvas (U(tn) e U*(tn)) e o seu inverso, são geradas. Deste modo, como o resultado da interação entre as mesmas, obtêmse o ponto aproximado da mudança abrupta na mediana da série, caso o valor 
encontre-se dentro do intervalo de confiança estatística $1,96<u(t n)<1,96$, para o qual 1,96 corresponde a $a=0,05$. Ou seja, o ponto aproximado do início de uma tendência é detectado quando a curva $U($ tn) cruza os limites de confiança ao nível de $95 \%$, onde $a=0,05$.

Assim como nos índices de precipitação relacionados à intensidade das chuvas, para o cálculo do teste não paramétrico de $M K$ foi empregado o software Climap.

A etapa final consistiu na geração dos mapas para cada índice, na qual se representou a localização geográfica de cada estação pluviométrica com base em suas respectivas coordenadas geográficas. Para este fim, foi utilizado o software de geoprocessamento ArcGis 9.3., licenciado junto ao laboratório de Sensoriamento Remoto e Geoprocessamento (SERGEO), locado na Universidade Federal de Pernambuco (UFPE).

\section{5 ÍNDICES DE PRECIPITAÇÃO E ANOMALIAS DE TSM}

Em razão do clima da região semiárida sofrer influência dos fenômenos associados às anomalias de TSM, a exemplo do dipolo do oceano Atlântico e anomalias do oceano Pacífico (El Niño/La Niña), optou-se por correlacionar os índices dependentes da precipitação com dados destas anomalias TSM.

Os índices utilizados foram DCS, DCC e PRCPTOT, para o posto de Araripina-PE, foram correlacionados com os dados de TSM (SOI, Niño 3, TNA, TSA, ONI, Niño $1+2$, Niño 4, Niño 3,4) para o período de 1963 a 2014, obtidos junto à National Oceanic and Atmospheric Administration (NOAA, 2017). Optouse também por realizar uma análise de tendência para as anomalias de TSM do Pacífico e dipolo do Atlântico.

Empregou-se o método Pearson para avaliar a correlação entre os índices climáticos e as anomalias de TSM, assim como seu nível de significância estatística, também conhecido como Coeficiente de Correlação do Momento Produto (FIGUEIREDO FILHO; SILVA JÚNIOR, 2009). O coeficiente de correlação populacional (parâmetro) $\rho$ e sua estimativa amostral estão intimamente relacionados com a distribuição normal bivariada, cuja função densidade de probabilidade é dada pela equação 4:

$$
f_{X, Y}(X, Y)=\frac{1}{2 \pi \sigma_{X} \sigma_{Y} \sqrt{1-\rho^{2}}} \exp \left\{-\frac{1}{2\left(1-\rho^{2}\right)}\left[\left(\frac{X-\mu_{X}}{\sigma_{X}}\right)-2 \rho\left(\frac{Y-\mu_{Y}}{\sigma_{Y}}\right)+\left(\frac{Y-\mu_{Y}}{\sigma_{Y}}\right)^{2}\right]\right\}
$$

Sendo que $\rho_{X, Y}=\rho=\frac{\operatorname{COV}(X, Y)}{\sigma_{X} \sigma_{Y}}=\frac{\sigma_{X, Y}}{\sigma_{X} \sigma_{Y}}$ o parâmetro populacional onde:

$\operatorname{COV}(X, Y)$ é a covariância entre $X$ e $Y ; \sigma_{-} X$ é o desvio padrão de $X ; \sigma_{-} Y$ é o desvio padrão de $\mathrm{Y}$.

O Estimador de Máxima Verossimilhança é dado pela equação 5: 


$$
\hat{\rho}_{X, Y}=\hat{\rho}=\frac{\sum_{i=1}^{n}(X i-\bar{X})(Y i-\bar{Y})}{\sqrt[n]{\sum_{i=1}^{n} \frac{(X i-\bar{X})^{2}}{n} \sqrt{\sum_{i=1}^{n} \frac{(Y i-\bar{Y})^{2}}{n}}}}=\frac{\sum_{i=1}^{n}\left(X_{i}-\overline{X)\left(Y_{I}-\bar{Y}\right)}\right.}{n \hat{\sigma}_{X} \hat{\sigma}_{Y}}
$$

Em que: $n$ é o número de observações da amostra; $X$ é a média aritmética de $X$; Y é a média aritmética de $\mathrm{Y}$.

O coeficiente de correlação também pode ser interpretado em termos de $\rho^{\wedge}{ }^{2}=R^{2}$, denominado coeficiente de determinação ou de explicação. Quando multiplicado por $100,0 \rho^{\wedge}{ }^{2}=R^{2}$ fornece a percentagem da variação em $Y$ (variável dependente), que pode ser explicada pela variação em $X$ (variável independente), ou seja, o quanto de variação é comum às duas variáveis. 0 coeficiente de determinação é a relação entre a variação explicada pelo modelo linear $\left(Y^{\wedge}=a^{\wedge}+\beta{ }^{\wedge} X\right.$, em que $a{ }^{\wedge}$ e $\beta{ }^{\wedge}$ são constantes) e a variação total.

A significância do coeficiente de correlação foi avaliada a partir do teste de hipótese t-Student, para os níveis de significância de 1\%,5\% e $10 \%$ e graus de liberdade de $(n-2)$. As rejeições às hipóteses nulas h0 irão identificar a existência de correlação linear entre as combinações realizadas. Para testar a hipótese de que o coeficiente de correlação linear é igual a zero, tem-se que: H_0: $\rho=0$ e H_1: $\rho \neq 0$, conforme a equação 6:

$$
t=\frac{\hat{\rho} \sqrt{n-2}}{\sqrt{1-\widehat{\rho}^{2}}} \sim t_{n-2}
$$

Em que: t_0 é a estatística do teste; $n$ é o tamanho da amostra; $r$ é a estimativa do coeficiente de correlação linear.

Sob o pressuposto da hipótese nula $H_{-} 0: \rho=0$. A hipótese nula é rejeitada se:

$$
\left|t_{0}\right|>t \alpha / 2(n-2)
$$

\section{RESULTADOS E DISCUSSÃO}

\section{1 ÍNDICES DE PRECIPITAÇÃO}

A distribuição dos índices relacionados a intensidade diária da precipitação pode ser visualizada na figura 2 . São índices que medem a frequência de determinados limiares de chuvas e indicam se há algum tipo de tendência estatisticamente significante. É possível observar que os sinais de tendência assim como a significância estatística varia espacialmente para todos os volumes analisados. Os dias com chuva $\geq 1 \mathrm{~mm}$, por exemplo, apresentam incremento significante para o posto pluviométrico de Serrita (2), enquanto o de Moreilândia apresenta tendência de redução.

As mudanças mais significativas foram observadas para os limiares de precipitação entre 10 (Pr10) e $20 \mathrm{~mm}$ (Pr20). Para o Pr10, observa-se que 66\% das estações pluviométricas indicam tendência de redução das chuvas com 
intensidade de $\geq 10 \mathrm{~mm}$, porém quando são analisadas apenas as que apresentaram significância estatística a quantidade cai para 50\%, concentradas principalmente na porção nordeste da região. Para o Pr20, as alterações ocorrem para a maior parte da região, uma vez que $66 \%$ dos postos indicam tendência negativa estatisticamente significante. Ressalta-se que as tendências negativas sobre limiares entre 10 e $20 \mathrm{~mm}$ tem maior potencial de impactos sobre a disponibilidade hídrica. De acordo com Sanches e Fisch (2014), estes volumes são mais comuns e contribuem para manutenção equilibrada dos processos químicos, físicos e biológicos de uma determinada área.

Quanto as precipitações entre 60 e $100 \mathrm{~mm}$, estes eventos pluviométricos são enquadrados como extremos climáticos que, geralmente, a depender da estrutura das cidades, tem alto potencial de destruição devido aos alagamentos e deslizamentos de terras. Para o Pr60 e Pr80, verificou-se tendências estatisticamente significantes. O posto de Santa Cruz, por exemplo, apresentou tendência positiva com significância para as precipitações $\geq 60$ e 80 $\mathrm{mm}$, enquanto que para o limiar $\geq 100 \mathrm{~mm}$ a tendência não apresentou significância. Entre as tendências negativas, destaca-se o posto de Serrita (2), que foi o único que indicou que a alteração é significante para o limiar de 60 $\mathrm{mm}$.

O predomínio das tendências positivas para os extremos climáticos de precipitação intensas também foi observado por Santos e Manzi (2011) para o estado do Ceará e por Nóbrega, Farias e Santos (2015) para Pernambuco. Outro ponto também constatado nos trabalhos mencionados corresponde a variabilidade espacial para os sinais de tendência e magnitude estatística.

Vale ressaltar que, dentro do contexto do aquecimento global, os extremos positivos de precipitação tendem a se tornar mais frequentes. $O$ aquecimento adicional contribui para o aumento da capacidade de retenção de vapor de água por parte da atmosfera, fenômeno que alonga os períodos secos e que favorece a ocorrência de chuvas torrenciais graças a maior quantidade de água armazenada na forma de vapor (IPCC, 2013). Por outro lado, não é seguro afirmar que as mudanças observadas resultem das mudanças climáticas, visto que existem outras variáveis atmosféricas que podem produzir este tipo de resultado, como as anomalias de TSM destacadas Santos e Manzi (2011) e que serão melhor discutidas no decorrer do presente estudo. 


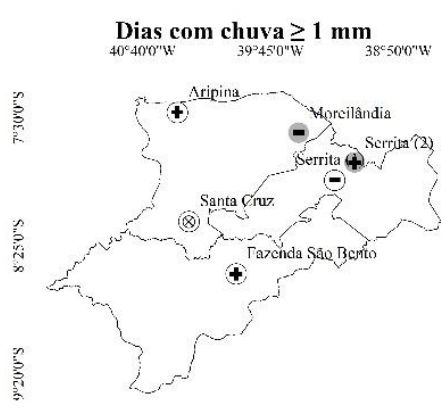

Dias com chuva $\geq 60 \mathrm{~mm}$

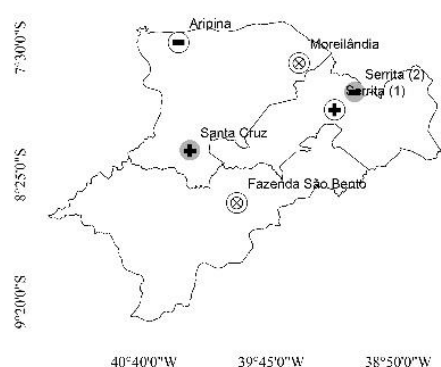

Tendência e significância estatística

- Tendência negativa com significância

- Tendência positiva com significância

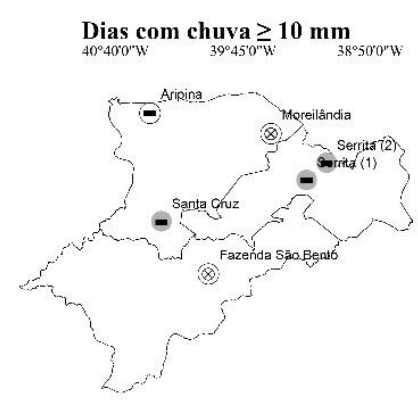

Dias com chuva $\geq 80 \mathrm{~mm}$

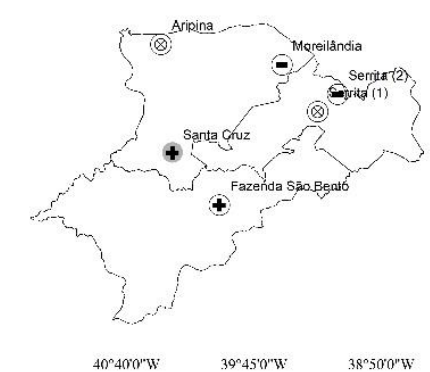

Dias com chuva $\geq 20 \mathrm{~mm}$

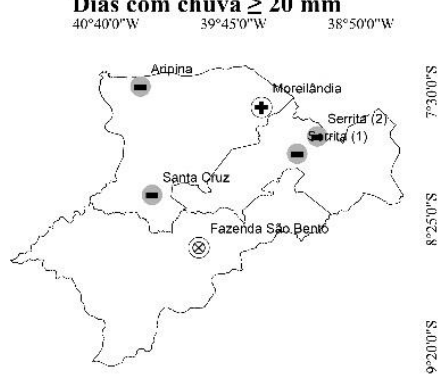

Dias com chuva $\geq 100 \mathrm{~mm}$

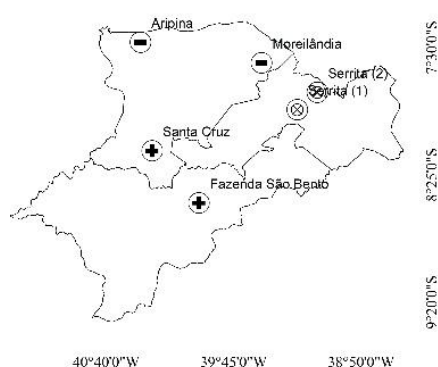

Figura 2 - Distribuição espacial das estações pluviométricas nas microrregiões de Araripina, Petrolina e Salgueiro.

Quanto aos índices referentes ao número de dias consecutivos secos (DCS), número de dias consecutivos chuvosos (DCC) e precipitação total anual (PCRTOT), estes são expostos na figura 3. Destaca-se inicialmente que os resultados obtidos indicaram que a região apresenta uma média de 116 dias consecutivos secos e 3,4 dias consecutivos úmidos. De maneira geral, os resultados sugerem que as chuvas na região são concentradas em poucos dias, com longos períodos secos. Silva, Pereira e Almeida (2012) pontuaram que os reduzidos dias de precipitações no Semiárido ocorrem entre os meses de dezembro e abril. Uma das principais características das chuvas na região, segundo os autores, refere-se sua forte intensidade e curta duração.

A análise estatística sobre frequência de dias secos e úmidos e para precipitação total anual revela que há uma significativa variação espacial das tendências. No que se refere ao índice DCS, $66 \%$ dos postos apresentaram tendência com significância estatística. Destes, $50 \%$ referem-se a tendência negativa e o restante a positiva. Chama atenção os postos de Serrita (1) e Serrita (2), que apresentaram tendências contrárias apesar da relativa proximidade $(20 \mathrm{~km})$ quando comparado as outras estações. Este resultado reforça o quão variável é a precipitação na região e sua influência sobre as condições de aridez e umidade.

Quanto ao DCC, de maneira geral, este índice indica que houve tendência de aumento das condições de umidade para as regiões, uma vez que verificouse tendência positiva para $66 \%$ dos postos pluviométricos. É importante frisar que este percentual cai para $50 \%$ quando considerados os postos que apresentaram significância estatística para as alterações observadas em suas 
séries. A estação localizada em Fazenda São Brito apresentou tendência negativa para o DCS e positiva para o DCC, se destacando em relação às demais. Esta combinação reforça a tendência de mudança para esta localidade específica. De modo geral, os resultados corroboram, em parte, os encontrados por Haylock et al. (2006), que verificaram aumento das condições de umidade para a região Nordeste, embora se faça necessário salientar que o estudo dos autores foi desenvolvido de maneira mais generalista para a região, uma vez que só utilizaram em suas análises apenas três postos pluviométricos.

Em relação ao índice PRCPTOT, que refere-se ao total de chuvas por ano, este apresenta um padrão diferente dos índices anteriores. Inicialmente, é possível observar que $86 \%$ das estações pluviométricas apresentaram redução da precipitação anual, com apenas o posto de Santa Cruz não apresentando nenhum tipo de tendência. Quando considerados apenas os que apresentaram significância estatística, este percentual cai para 33\%. Diferentemente do que ocorreu com os índices anteriores, para o PRCPTOT não se verificou nenhuma estação com tendência positiva. Ou seja, ainda que os índices DCS e DCC indiquem alterações na recorrência de períodos secos ou úmidos, para a precipitação total as variações, quando significantes, apontam que houve redução da precipitação em algumas localidades da região estudada

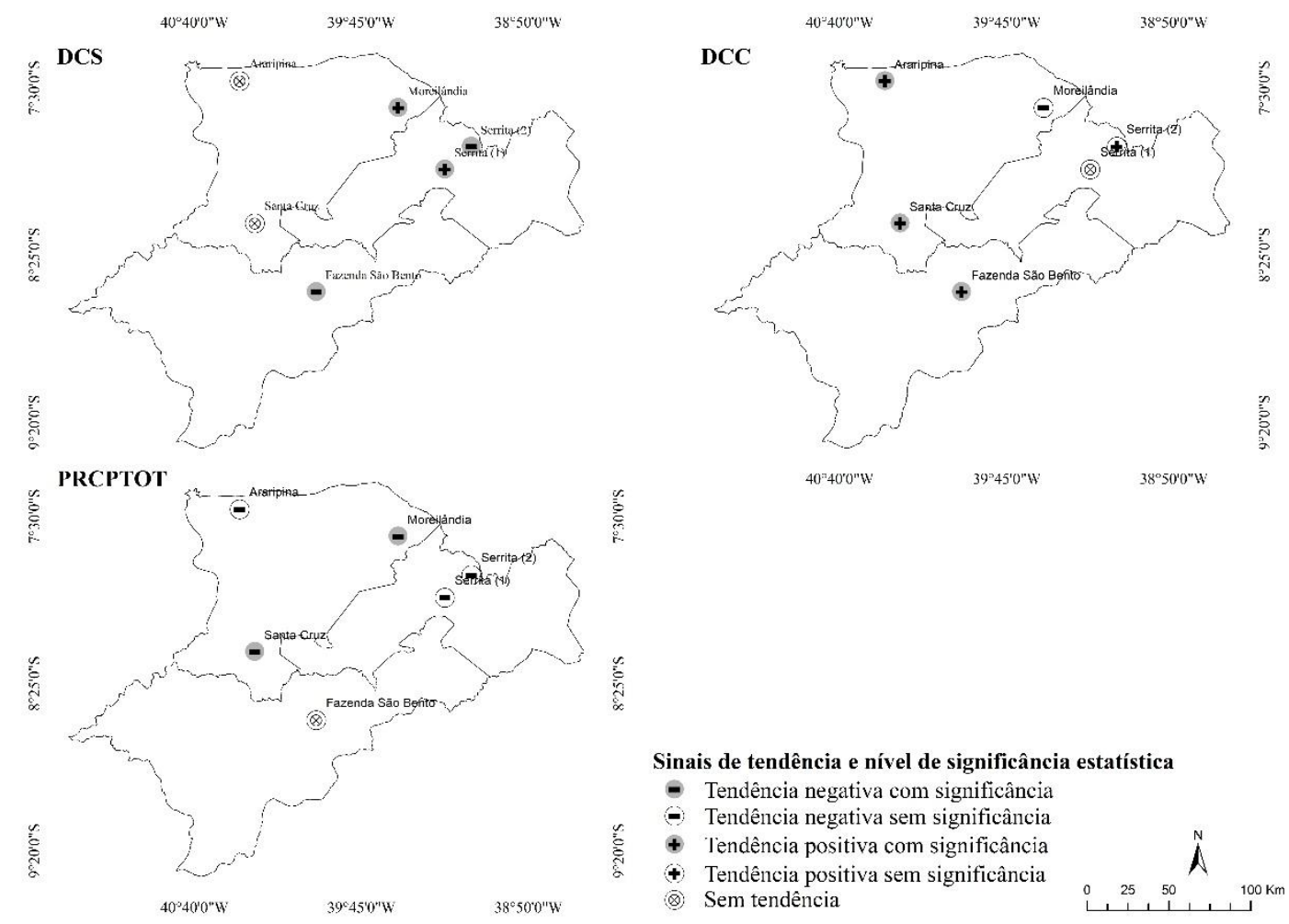

Figura 3 - Distribuição espacial das estações pluviométricas nas microrregiões de Araripina, Petrolina e Salgueiro, assim como nível de significância estatísticas das séries temporais para os índices relativos ao número de dias consecutivos secos, número de dias consecutivos chuvosos e precipitação total.

Ressalta-se que a sequência de dias secos ou chuvosos e até mesmo a quantidade total de chuvas durante 0 ano nas regiões semiáridas sofre 
influência importante de sistemas atmosféricos resultantes do padrão termodinâmico dos oceanos Atlântico e Pacífico, entre os quais pode-se destacar a ZCIT, (oceano Atlântico) e El Niño e La Niña, estes dois últimos oriundos oceano Pacífico (NÓBREGA; SANTIAGO; SOARES, 2016). Para o presente estudo, tal influência sobre o padrão climático da região também foi medida, conforme tabela 3, que expõe os resultados da correlação dos diferentes setores do Atlântico e Pacífico, assim como índices de anomalias, com os índices DCS, DCC e PRCPTOT.

De modo geral, é possível observar que as séries de todos os postos pluviométricos correlacionaram-se com um dos setores e índices do Atlântico e Pacífico, para pelo menos um ou mais índices de chuva. Verifica-se que $80 \%$ das correlações com as anomalias de TSM foram superiores a $10 \%$, ou seja, evidenciando algum nível de influência, embora sem significância estatística. Para correlações com valor igual ou superior a $20 \%$, constata-se significância estatística entre 90 e $95 \%$ de confiança.

Outro ponto importante corresponde ao grau influência das anomalias de TSM sobre cada índice dependente da precipitação. É notável que o índice PRCPTOT, que correspondente a precipitação total anual, é o mais influenciado quando se leva em consideração o nível de significância estatística da correlação (90 a 95\%) e é também o que apresenta maiores valores de correlação. Isto pode ser explicado pelo tempo de resposta da atmosfera às mudanças de temperatura de superfície do mar, que não ocorre de forma imediata para regiões afastadas. Ou seja, os índices pluviométricos como DCS e DCC, calculados em escala diária, tendem a apresentar menor correlação, muitas vezes sem significância estatística.

Também é preciso levar em consideração a atuação de outros sistemas atmosféricos e sazonalidade dos sistemas principais. Segundo Assis, Souza e Sobral (2015), a precipitação pluviométrica é controlada, principalmente, pelas instabilidades associadas as Frentes Frias, Vórtices Ciclônicos de Ar Superior (VCAS), Zona de Convergência do Atlântico Sul (ZACAS), Zona de Convergência Intertropical (ZCIT) El Ninõ e La Niña. Destes, a ZCIT, El Ninõ e La Niña são os principais responsáveis pela ocorrência de anos mais úmidos ou pelos longos períodos de seca, o que explica parte dos resultados encontrados. No caso da ZCIT, o Dipolo do Atlântico é capaz de afetar a posição da linha de convergência, que quando encontra-se ao sul da linha do Equador, colabora para a ocorrência de chuvas no Semiárido, com intensidade maior nas regiões mais ao norte devido à maior proximidade com a zona confluência dos ventos úmidos. Quanto ao El Niño, este sistema resulta do aquecimento anômalo das águas superficiais do Pacífico Sul, ocasionado pela desaceleração dos ventos de baixa altitude que sopram de oeste para leste, dinâmica contrária à do La Niña (ANDREOLI; KAYANO, 2007; FERREIRA; MELLO, 2005).

O El Niño é apontado como um dos principais responsáveis pelos anos considerados secos ou muito secos no Nordeste brasileiro, sobretudo quando associado ao dipolo do Atlântico, neste caso quando coincide com os anos em que a da ZCIT não avança em direção ao hemisfério Sul (Fase Positiva do Atlântico). Assim, fica claro que apesar da ocorrência de El Niños, sejam fracos, moderados ou fortes, a intensidade da estiagem ou a configuração de um ano onde as precipitações encontram-se próximas da normalidade, depende da posição da linha de convergência intertropical que, quando posicionada mais ao 
norte do equador, pode contribuir de forma determinante para o agravamento das secas na região. Num sentido contrário, em anos onde a ZCIT se posiciona ao sul do Equador, mesmo com ocorrência de El Ninõs, os efeitos podem ser minimizados ou até mesmo não sentidos, principalmente sob a perspectiva do setor agropecuário (NÓBREGA; SANTIAGO; SOARES, 2016; SANTOS; BRITO, 2007).

As recorrentes secas que vêm afetando o semiárido nordestino são frequentemente associadas aos possíveis efeitos das mudanças climáticas, sobretudo nas últimas décadas, quando os debates sobre a questão ganharam força. Por outro lado, a complexidade dos diferentes sistemas atmosféricos, que atuam desde a escala regional a global, ainda dificultam os prognósticos sobre o clima. Os resultados encontrados na presente pesquisa, cujo recorte temporal da análise é de 51 anos, sugerem que os fenômenos atmosféricos relacionados a estiagens ou chuvas acima da média, para esse período, foram determinados pela atuação de sistemas atmosféricos que atuaram em escala global. Ou seja, a resposta da precipitação no semiárido às anomalias de TSM do Pacífico explica em parte os resultados encontrados na correlação realizada entre as variáveis. Este é um indicativo de que as tendências observadas nos índices analisados não representam necessariamente uma mudança no padrão climático da região, mas a atuação persistente das anomalias de TSM. 
Tabela 3 - Correlação dos índices número de dias consecutivos secos (DCS), número de dias consecutivos chuvosos (DCC) e precipitação total anual (PRCPTOT) com as anomalias de Temperatura de Superfície do Mar e sua influência sobre a precipitação nas microrregiões de Araripina, Petrolina e Salgueiro.

\begin{tabular}{|c|c|c|c|c|c|c|c|c|}
\hline Araripina & TNA & TSA & ONI & SOI & $\begin{array}{c}\text { Niño } 1+ \\
2\end{array}$ & Niño 3 & Niño 3.4 & Niño 4 \\
\hline DCS & 0,01 & 0,16 & 0,12 & 0,01 & $-0,06$ & 0,04 & 0,07 & 0,09 \\
\hline DCC & $0,24 *$ & 0,16 & $-0,1$ & 0,15 & 0,14 & 0,05 & $-0,06$ & $-0,10$ \\
\hline PRCPTOT & $0,23 *$ & 0,13 & $-0,20$ & $0,20 *$ & $\begin{array}{c}-0,3 * * \\
\text { Niño } 1+\end{array}$ & $-0,26 *$ & $-0,22 *$ & $-0,21 *$ \\
\hline Fazenda S. Bento & TNA & TSA & ONI & SOI & 2 & Niño 3 & Niño 3.4 & Niño 4 \\
\hline DCS & -0.09 & $-0.45 * *$ & $0.36 * *$ & $-0.34 * *$ & 0.07 & 0.21 & $0.27 *$ & 0.16 \\
\hline DCC & 0.14 & 0.10 & -0.12 & 0.09 & 0 & -0.06 & -0.07 & 0.01 \\
\hline $\begin{array}{l}\text { PRCPTOT } \\
\text { Moreilândia }\end{array}$ & $\begin{array}{l}-0.18 \\
\text { TNA }\end{array}$ & $\begin{array}{l}0.14 \\
\text { TSA }\end{array}$ & $\begin{array}{c}0.31 * * \\
\text { ONI }\end{array}$ & $\begin{array}{c}0.30 * * \\
\text { SOI }\end{array}$ & $\begin{array}{c}-0.24 * \\
\text { Niño } 1+ \\
2\end{array}$ & $\begin{array}{l}-0.30 * * \\
\text { Niño } 3\end{array}$ & $\begin{array}{c}-0.29 * * \\
\text { Niño } 3.4\end{array}$ & $\begin{array}{l}-0.20 * \\
\text { Niño } 4\end{array}$ \\
\hline DCS & 0.21 & 0.11 & 0.06 & 0 & 0.07 & 0.13 & 0.10 & 0.11 \\
\hline DCC & 0.04 & -0.02 & -0.1 & 0.19 & -0.14 & -0.14 & -0.13 & -0.12 \\
\hline $\begin{array}{l}\text { PRCPTOT } \\
\text { Santa Cruz }\end{array}$ & $\begin{array}{c}-0.19 * \\
\text { TNA }\end{array}$ & 0.07 & $\begin{array}{c}-0.23 * \\
\text { ONI }\end{array}$ & $\begin{array}{c}0.33^{* *} \\
\text { soI }\end{array}$ & $\begin{array}{c}-0.42 * * \\
\text { Niño } 1+ \\
2\end{array}$ & $\begin{array}{l}-0.40 * * \\
\text { Niño } 3\end{array}$ & $\begin{array}{c}-0.30 * * \\
\text { Niño } \mathbf{3 . 4}\end{array}$ & $\begin{array}{l}-0.28^{* *} \\
\text { Niño } 4\end{array}$ \\
\hline DCS & $0.23 *$ & -0.07 & 0.21 & -0.13 & $0.39 * *$ & $0.30 * *$ & 0.22 & 0.16 \\
\hline DCC & 0.16 & 0 & -0.08 & 0.18 & -0.11 & -0.10 & -0.09 & -0.06 \\
\hline PRCPTOT & -0.15 & 0.12 & $-0.26 *$ & $0.30 * *$ & $\begin{array}{c}-0.45^{* *} \\
\text { Niño } 1+\end{array}$ & $-0.42 * *$ & $-0.32 * *$ & $-028 * *$ \\
\hline Serrita (1) & TNA & TSA & ONI & SOI & 2 & Niño 3 & Niño 3.4 & Niño 4 \\
\hline DCS & $0.41^{* *}$ & 0 & 0.04 & -0.17 & $0.27 * *$ & 0.15 & 0.08 & 0.08 \\
\hline DCC & 0.08 & 0.14 & -0.1 & 0.17 & -0.15 & -0.13 & -0.1 & -0.05 \\
\hline РRCPTOT & $-0.23 *$ & 0.07 & $0.35^{* *}$ & $0.43 * *$ & $\begin{array}{c}-0.46 * * \\
\text { Niño } 1+\end{array}$ & $0.46 * *$ & $-0.41 * *$ & $-0.37 * *$ \\
\hline Serrita (2) & TNA & TSA & ONI & SOI & 2 & Niño 3 & Niño 3.4 & Niño 4 \\
\hline DCS & $-0.27 *$ & -0.20 & $0.24 *$ & $-0.29 * *$ & 0.01 & 0.13 & 0.18 & 0.08 \\
\hline DCC & 0.19 & 0.03 & -0.13 & 0.19 & -0.1 & -0.10 & -0.14 & -0.09 \\
\hline PRCPTOT & $-0.24 *$ & 0.10 & $0.34 * *$ & $0.36 * *$ & $-0.37 * *$ & $-0.42 * *$ & $-0.39 * *$ & $-0.35 * *$ \\
\hline
\end{tabular}

*Significância estatística ao nível de $90 \%$. **Significância estatística ao nível de $95 \%$.

\subsection{TESTE DE MANN-KENDALL APLICADO AO PERÍODO CHUVOSO}

A distribuição espacial para as tendências correspondentes ao teste sequencial de Mann-Kendall (MK) para as estações inseridas nas microrregiões de Araripina, Petrolina e Salgueiro pode visualizada na Figura 4. Verifica-se que apenas um dos postos analisados (Fazenda São Bento) não apresentou tendência negativa. Quando se leva em consideração as tendências com significância estatística ao nível de $95 \%$, apenas os postos de Santa Cruz e Moreilândia são enquadrados nesse limiar, indicando que nestas localidades específicas houve redução da precipitação entre 1963 e 2014. Os resultados sugerem, em um primeiro momento, que pode haver na região uma eventual alteração climática. Isto é reforçado quando se leva em consideração a confiabilidade do teste de MK para este tipo de análise. 
Por outro lado, a tese de que a tendência de redução da precipitação para as localidades de Moreilândia e Santa Cruz esteja relacionada a mudanças climáticas perde força quando os resultados são comparados com o índice PRCPTOT, analisado anteriormente. Conforme pode ser observado, o padrão de distribuição espacial das tendências para o teste de MK é exatamente o mesmo verificado para o índice PCRPTOT, que também é baseado na sequência histórica da precipitação anual. Assim, o índice PCRPTOT foi o que apresentou maiores correlações com significância estatística com as anomalias de TSM dos oceanos Atlântico e Pacífico tropicais. Nesse sentido, a comparação entre os resultados sugere que a redução da precipitação para essas localidades é um reflexo da sazonalidade dos principais sistemas que atuaram desfavoravelmente na região de forma persistente. Isto é reforçado pelo padrão observado nas estações no entorno, que em maioria também apresentaram tendência negativa, porém sem significância estatística.

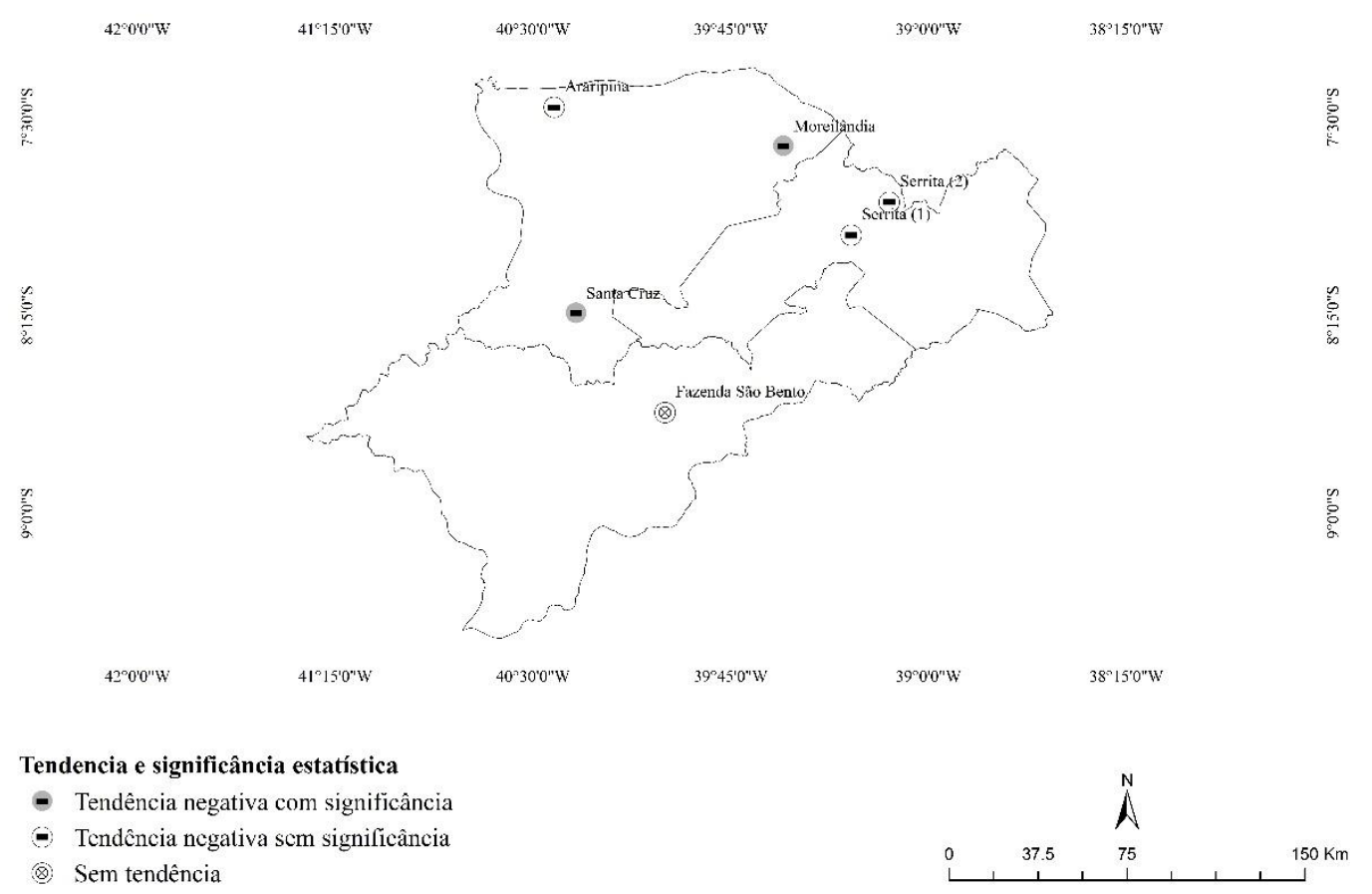

Figura 4 - Distribuição espacial dos sinais de tendência referente ao teste de MannKendall para as microrregiões de Araripina, Petrolina e Salgueiro.

O padrão temporal da precipitação das estações que apresentaram significância estatística para o teste de MK é exposto na figura 5, a qual permite identificar o momento em que a mudança se iniciou, ou seja, quando a linha $\mathrm{U}(\mathrm{t})$ cruza o limite de significância estatística ao nível de $95 \%$. Para o posto pluviométrico de Moreilândia, a mudança se dá no ano de 1973 e se mantém até o final da série. Observa-se que em 1963 a precipitação acumulada foi em torno de $1.000 \mathrm{~mm}, 67,5 \%$ superior à média histórica da região (597 mm). Este pico foi muito importante para a configuração do resultado, principalmente quando se leva em consideração que a média histórica do posto pluviométrico é de 640 mm, limiar que não foi alcançado apenas em 1969 e 1972. 
Apesar da notável influência dos extremos pluviométricos no início da série temporal de Moreilândia, verifica-se que as chuvas na região seguem uma tendência de redução. Quando se considera toda a série histórica, em pelo menos $45 \%$ do período as chuvas observadas foram iguais ou inferiores a 600 $\mathrm{mm}$ e em $17 \%$ igual ou inferiores a $400 \mathrm{~mm}$. São observados três eventos onde as chuvas foram de cerca de $200 \mathrm{~mm}$, para os anos de 1993, 2003 e 2012. Vale ressaltar que os eventos de precipitação iguais ou inferiores a $400 \mathrm{~mm}$ e principalmente os de $200 \mathrm{~mm}$ foram importantes para a aumento do coeficiente angular da reta de tendência. Outro ponto importante é que a maior parte dos picos de precipitação $\geq 1.000$ (62,5\%) concentram-se após o ano de 1973, quando a mudança se inicia. Ainda assim, não ocorreram em quantidade suficiente para fazer com que a linha $U(t)$ se posiciona-se mais próxima ao limite de significância estatística. $\mathrm{Na}$ verdade verifica-se que há maior afastamento justamente pela maior frequência de precipitações entre 200 e 400 $\mathrm{mm}$ no decorrer do período.

Quanto ao posto de Santa Cruz, a mudança também ocorreu durante a década de 1970, mais precisamente em 1978. Observa-se que a linha $U(t)$ se mantém muito próxima ao limite de significância estatística, até mesmo retornando ao limiar que indica volta ao padrão anterior, como verificado em 1983. No ano seguinte, novamente a linha $U(t)$ cruza o limite negativo de significância estatística e se distancia sistematicamente até 1998. A partir desse ano, até 2014, a linha fica muito próxima o limite de significância. O padrão de variação da linha $U(\mathrm{t})$ pode ser explicado pela constante alternância entre anos com precipitação superior e inferior a $400 \mathrm{~mm}$. Diferente do que ocorreu com o posto de Moreilândia, a quantidade de eventos de chuvas $\geq 1.000$ é bem menor, ocorrendo apenas no ano de 1985, o que contribuiu inclusive para que a linha $\mathrm{U}(\mathrm{t})$ retorna-se para o limiar indicativo de normalidade.

De maneira geral, as mudanças observadas na série temporal de precipitação para o posto de Moreilândia e Santa Cruz ocorreram entres as décadas de 1970 e 1980, período marcado pelo grande desvio climático associado a Oscilação Decadal do Pacífico (KAYANO; OLIVEIRA; ANDREOLI, 2009). O fenômeno é ratificado por parte dos resultados de correlação de TSM encontrados no presente estudo, uma vez que os postos de Moreilândia e Santa Cruz apresentaram correlação estatisticamente significantes para as anomalias de TSM Atlântico e Pacífico, um indicativo de que a alteração observada é reflexo da persistência de sistemas atmosféricos como a ZCIT e El Niño. 

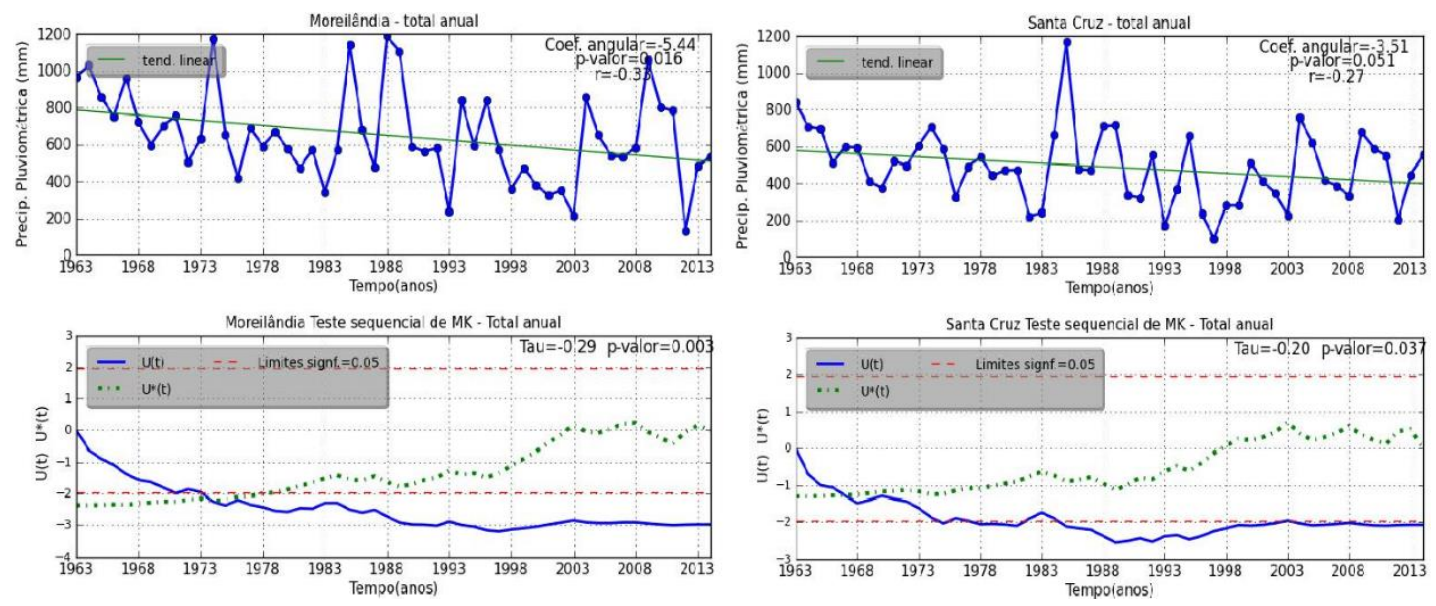

Figura 5 - Teste de Mann-Kendall para a precipitação anual das estações pluviométrica localizadas em Moreilândia-PE e Santa Cruz-PE.

Como as chuvas no semiárido pernambucano, de modo geral, concentram-se entre os meses de dezembro (pré-estação chuvosa) a abril (estação chuvosa), optou-se também por aplicar o teste de MK para este período específico, como pode ser observado na tabela 4, que também expõe o tipo de tendência e o nível de significância estatística. É possível constatar que além dos postos pluviométricos de Moreilândia e Santa Cruz, que foram os únicos que apresentaram significância na análise anual, outros três (Araripina, Serrita (1) e Serrita (2)) passaram indicar tendência negativa significante para pelo menos um dos meses do período chuvoso, onde a única exceção foi o posto localizado na Fazenda São Bento, que não apresentou significância para nenhum dos meses.

Observa-se que o mês de março é o mais afetado com as reduções das chuvas quando se leva em consideração todas as estações pluviométricas, uma vez que, dos seis postos analisados, quatro apresentam tendência negativa estatisticamente significante. Vale ressaltar que todos os postos apresentaram redução para um ou dois meses, sendo estes concentrados dentro do período onde as precipitações são mais intensas, no caso fevereiro, março e abril. 0 posto pluviométrico de Araripina se destaca entre os demais, visto que é o único que aponta tendência negativa significante para todos os meses analisados.

Deste modo, ainda que para análise anual apenas dois postos tenham apresentado tendência de mudança no padrão, verifica-se que este número se eleva ao se considerar o período chuvoso, principal responsável pelo aumento da disponibilidade hídrica para os sistemas naturais e socioeconômicos. Por outro lado, é importante reforçar que as séries pluviométricas de todos os postos correlacionaram-se significativamente com um dos índices de anomalia de TSM, até mesmo o de Fazenda São Bento, que não apresentou tendência significante para a análise anual e do período chuvoso. 
Tabela 4 - Teste Mann-Kendall para o período chuvoso para as microrregiões de Araripina, Petrolina e Salgueiro.

\begin{tabular}{lccccc}
\hline \multicolumn{1}{c}{ Estações } & Dezembro & Janeiro & Fevereiro & Março & Abril \\
Araripina & TN* & TN* & TN* & TN* & TN* \\
Fazenda S. Bento & ST & TP & TP & TN & ST \\
Moreilândia & ST & TP & TN* & TN* & TN \\
Santa Cruz & ST & TN & ST & TN & TN* \\
Serrita (1) & ST & ST & ST & TN* & TN \\
Serrita (2) & ST & ST & ST & TN* & TN \\
\hline
\end{tabular}

TN* - Tendência negativa com significância TP - Tendência positiva sem significância TN - Tendência negativa sem significância ST - Sem tendência.

\section{CONCLUSÕES}

Verificaram-se tendências negativas significantes para os valores de precipitação diária entre 10 e $20 \mathrm{~mm}$, dentre os mais comuns ao tipo de clima (semiárido) da região. Para as precipitações $\geq 60, \geq 80$ e $\geq 100 \mathrm{~mm}$, que se enquadram como eventos climáticos extremos, de maneira geral, observaramse tendências positivas e negativas. Quando considerados os estatisticamente significantes, o posto de Santa Cruz indicou tendência de aumento para os extremos de 60 e $80 \mathrm{~mm}$, enquanto Serrita (1) apresentou tendência negativa. Quanto as chuvas $\geq 100 \mathrm{~mm}$, não constatou-se tendência estatisticamente significante.

Quanto a estimativa do índice DCS, constatou-se tendências positivas para os postos de Moreilândia e Serrita (1) e negativa para Fazenda São Bento e Serrita (2). Em relação ao DCC, os resultados indicaram aumento da sequência de dias úmidos (precipitação $\geq 1 \mathrm{~mm}$ ) para os postos de Araripina, Santa Cruz e Fazenda são Bento. Para o índice PRCPTOT houve tendência generalizada de diminuição da precipitação. Entretanto, apenas as tendências observadas para Santa Cruz e Moreilândia foram estatisticamente significantes.

A correlação dos índices DCS, DCS e PRCPTOT demonstrou significativa influência dos sistemas atmosféricos oriundos do Pacífico (La Niña e El Niño) e Dipolo do Atlântico (ZCIT) sobre as respostas encontradas. Observou-se que os três índices apresentaram correlação significante principalmente para os setores do Pacífico. Dentre eles, destaca-se o PRCPTOT indicou correlação significante, de forma simultânea, para os quatro setores do Pacífico (Niño $1+2$, Niño 3, Niño 3.4, Niño 4). O PRCPTOT também foi o índice com maiores valores de correlação com as anomalias de TSM do Pacífico, o que demonstra a importância do referido oceano para controle da precipitação anual na região.

Quanto ao teste de $\mathrm{MK}$, aplicado para avaliar possíveis mudanças no clima, para a análise anual, cindo dos seis postos apresentaram tendência negativa. Entretanto, apenas os postos de Moreilândia e Santa Cruz indicaram que a tendência foi estatisticamente significante. A análise temporal para estes dois postos indicou que a mudança se iniciou entre 1970 e 1980, período que coincide com um intenso desvio climático decorrente de ODP.

Em relação a aplicação do teste de MK para o período onde ocorre a maior parte das chuvas, constatou-se que houve aumento do número de estações que apresentaram significância estatística em relação a análise anual. 
Todas as tendências significantes foram negativas para cinco dos seis postos, concentradas principalmente fevereiro, março e abril, para os quais se registra maiores valores de precipitação pluviométrica.

\section{AGRADECIMENTOS}

À Universidade Federal de Pernambuco e ao grupo de pesquisa Sensoriamento Remoto e Geoprocessamento, pela disponibilidade de toda estrutura física. À Fundação de Amparo à Ciência e Tecnologia de Pernambuco (FACEPE) pela bolsa de doutorado concedida ao autor..

\section{REFERÊNCIAS BIBLIOGRÁFICAS}

ALVARES, C. A. et al. Köppen's climate classification map for Brazil. Meteorologische Zeitschrift, v. 22, n. 6, p. 711-728, 2013.

ANDREOLI, R. V. et al. A influência da temperatura da superfície do mar dos Oceanos Pacifico e Atlântico na variabilidade de precipitação em Fortaleza. Revista Brasileira de Meteorologia, v. 19, n. 2, p. 337-344, 2004.

ANDREOLI, R. V.; KAYANO, M. T. A importância relativa do atlântico tropical sul e pacífico leste na variabilidade de precipitação do Nordeste do Brasil. Revista Brasileira de Meteorologia, v. 22, n. 1, p. 63-74, 2007.

ASSIS, J. M. .; SOUZA, W. .; SOBRAL, M. C. M. Climate analysis of the rainfall in the lower-middle stretch of the são francisco river basin based on the rain anomaly index. Revista Brasileira de Ciências, v. 2, n. 1, p. 188-202, 2015.

BARCELLOS, P. DA C. L. et al. Diagnóstico meteorológico dos desastres naturais ocorridos nos últimos 20 anos na cidade de Duque de Caxias. Revista Brasileira de Meteorologia, v. 31, n. 3, p. 319-329, 2016.

DE LOUREIRO, R. S. et al. Estudo dos eventos extremos de precipitação ocorridos em 2009 no estado do pará. Revista Brasileira de Meteorologia, v. 29, n. Especial, p. 83-94, 2014.

FERRARI, A. L.; VECCHIA, F. A. DA S.; COLABONE, R. DE O. Tendência e variabilidade anuais da temperatura e da pluviosidade em pirassununga-sp. Revista Brasileira de Climatologia, v. 6, n. September, p. 494-501, 2012.

FERREIRA, A. G.; MELLO, N. G. D. S. Perincipais sistemas atmosféricos atuantes sobre a região Nordeste do Brasil e a Influência dos oceanos Pacífico e Atlântico no clima da Região. Revista Brasileira de Climatologia, v. 1, n. 1, p. 15-28, 2005.

FLATO, M.; MUTTARAK, R.; PELSER, A. Women, Weather, and Woes: The Triangular Dynamics of Female-Headed Households, Economic Vulnerability, and Climate Variability in South Africa. World Development, v. 90, n. 17, p. 41-62, 2017.

HASTENRATH, S.; HELLER, L. Dynamics of climatic hazards in northeast Brazil. Quartely Journal Royal Meteorological Society, v. 103, n. 435, p. 77-92, 1977.

IBGE. Censo demográfico 2010 Instituto Brasileiro de Geografia e Estatística., 2010. 
<http://www.ibge.gov.br/home/estatistica/populacao/censo2010/default.shtm> . Acesso em 9 janeiro de 2016.

IPCC. Climate Change 2013: The Physical Science Basis. Contribution of Working Group I to the Fifth Assessment Report of the Intergovernmental Panel on Climate Change [Stocker, T.F., D. Qin, G.-K. Plattner, M. Tignor, S.K. Allen, ]. Boschung, A. Nauels, Y. Xia, V. Bex and P.M. Midgley (eds.)]. Cambridge University Press, Cambridge, United Kingdom and New York, NY, USA, 2013. 1535p.

INPE. Últimas Ocorrências de El Niños. <http://enos.cptec.inpe.br/tab_elnino.shtml>. Acesso em 15 de agosto de 2017 KANE, R. P. Prediction of droughts in north-east Brazil: Role of ENSO and use of periodicities. International Journal of Climatology, v. 17, p. 655-665, 1997.

KAYANO, M. T.; OLIVEIRA, C. P. DE; ANDREOLI, R. V. Interannual relations between South American rainfall and tropical sea surface temperature anomalies before and after 1976. International Journal of Climatology, v. 29, n. 10, p. 1439-1448, 2009.

MARENGO, J. A. et al. A seca e a crise hídrica de 2014-2015 em São Paulo. Revista USP, n. 106, p. 31-44, 2015.

MOURA, A. D.; SHUKLA, J. On the dynamics of droughts in northeast Brazil: Observations, theory and numerical experiments with a general circulation model. Journal of the Atmospheric Sciences, v. 38, n. 1, p. 2653-2675, 1981.

NOAA. National Oceanic and Atmospheric Administration. <https://www.esrl.noaa.gov/psd/data/climateindices/list/>. Acesso em 28 janeiro de 2016.

NOBRE, P.; SHUKLA, J. Variations of sea surface temperature, wind stress, and rainfall over the tropical Atlantic and South America. Journal of Climate, v. 9, n. 10, p. 2464-2479, 1996.

NÓBREGA, R. S.; FARIAS, R. F. DE L.; SANTOS, C. A. C. DOS. Variabilidade temporal e espacial da precipitação pluviométrica em Pernambuco através de índices de extremos climáticos. Revista Brasileira de Meteorologia, v. 30, n. 2, p. 171-180, jun. 2015.

NÓBREGA, R. S.; SANTIAGO, G. A. C. F.; SOARES, D. B. Tendência do Controle climático oceânico sob a variabilidade Temporal da Precipitação no Nordeste do Brasil. Revista Brasileira de Climatologia, v. 18, p. 276-292, 2016.

POLZIN, D.; HASTENRATH, S. CLIMATE OF BRAZIL'S NORDESTE AND TROPICAL ATLANTIC SECTOR: PREFERRED TIME SCALES OF VARIABILITY.

September 2013 - Ac. Revista Brasileira de Meteorologia, v. 29, n. 2, p. 153160, 2014.

SALVADOR, M. ANÁLISE DA VARIABILIDADE CLIMÁTICA NA NOVA FRONTEIRA AGRÍCOLA DO BRASIL: REGIÃO DO MATOPIBA. Campina Grande: Universidade Federal de Campina Grande (UFCG), 2014. 119. Tese de doutorado, Programa de pós-graduação em meteorologia, Campina Grande.

SANTOS, C. A. C. DOS; BRITO, J. I. B. DE. Análise dos índices de extremos para o semi-árido do Brasil e suas relações com TSM e IVDN TT - Analysis of indices 
of extremes for the semi-arid of Brazil and its relations with SST and NDVI. Revista Brasileira de Meteorologia, v. 22, n. 3, p. 303-312, 2007.

SANTOS, C. A. C. DOS; MANZI, A. O. Eventos Extremos de Precipitação no Estado do Ceará e Suas Relações Com a Temperetura dos Oceanos Tropicais. Revista Brasileira de Meteorologia, v. 26, n. 1, p. 157-165, 2011.

SERVAIN, J. Simple climatic indices for the tropical Atlantic Ocean and some applications. Journal of Geophysical Research, v. 96, n. 8, p. 15137-15146, 1991.

SILVA, F. B. R. et al. Zoneamento Agroecológico de Pernambuco - ZAPE. Recife: Embrapa Solos - Unidade de Execução de Pesquisa e Desenvolvimento - UEP Recife; Governo do Estado de Pernambuco (Secretaria de Produção Rural e Reforma Agrária). (Embrapa Solos. Documentos; no. 35). ZAPE Digital, CDROM. 2001.

SILVA, F. B. et al. Evidências de mudanças climáticas na região de transiçãoo Amazônia-Cerrado no Estado do Maranhão. Revista Brasileira de Meteorologia, v. 31, n. 3, p. 330-336, 2016.

SILVA, V. D. P. R. DA; PEREIRA, E. R. R.; ALMEIDA, R. S. R. Estudo Da Variabilidade Anual E Intra-Anual Da Precipitação Na Região Nordeste Do Brasil. Revista Brasileira de Meteorologia, v. 27, n. 2, p. 163-172, 2012.

XAVIER, D. R.; BARCELLOS, C.; FREITAS, C. M. DE. Eventos climáticos extremos e consequências sobre a saúde: o desastre de 2008 em Santa Catarina segundo diferentes fontes de informação. Ambiente \& Sociedade, v. 17, n. 4, p. 273-294, 2014. 